\title{
Effect of Different Bend Pipes on the Propagation Characteristics of Premixed Methane-Air Explosion in Confined Spaces
}

\author{
Jinwei Qiu $\mathbb{D},{ }^{1}$ Bingyou Jiang $\mathbb{D},{ }^{1,2}$ Mingyun Tang, ${ }^{1}$ Liang Zhou, ${ }^{1}$ and Bo Ren $^{3}$ \\ ${ }^{1}$ State Key Laboratory of Mining Response and Disaster Prevention and Control in Deep Coal Mines, Anhui University of Science \\ and Technology, Huainan, Anhui 232001, China \\ ${ }^{2}$ State Key Laboratory of Explosion Science and Technology, Beijing Institute of Technology, Beijing 100081, China \\ ${ }^{3}$ State Key Laboratory of Deep Coal Mining \& Environment Protection, Coal Mining National Engineering Technology \\ Research Institute, Huainan 232000, China
}

Correspondence should be addressed to Jinwei Qiu; jwqiu2000@163.com and Bingyou Jiang; cumtjiangby@163.com

Received 28 December 2020; Revised 13 January 2021; Accepted 28 January 2021; Published 26 February 2021

Academic Editor: Feng Xiong

Copyright (C) 2021 Jinwei Qiu et al. This is an open access article distributed under the Creative Commons Attribution License, which permits unrestricted use, distribution, and reproduction in any medium, provided the original work is properly cited.

To explore the effect of different bend pipes on the propagation characteristics of premixed methane-air explosion, the experimental explosion pipe system and numerical model were established. By adopting the comparative analysis of experiments and numerical modeling, it conducted researches on the overpressure evolution of gas explosion shock wave in pipes with different bends and obtained the expressions of attenuation coefficient of shock wave overpressure. The results showed that the change of pipe direction accelerated the attenuation of gas explosion shock wave. The propagation attenuation of gas explosion in the bend pipe was mainly affected by the bending angle and initial peak overpressure before bending. With the increase of the bending angle, the attenuation coefficient of gas explosion shock wave gradually increased. For the same bending angle, the attenuation coefficient of gas explosion shock wave increased with the increase of gas volume. The obtained coupling relationships between attenuation coefficient, bending angle, and initial peak overpressure before bending were useful for estimating the overpressure value after the bend. The results presented in this paper have important significance for the assessment of structures that have been damaged in the mine laneway of gas exploration accidents, further enriching the gas exploration spread theory.

\section{Introduction}

Gas explosions are one of the main hazards in coal mining, gas transportation, and related fields [1,2]. Pipes or roadways that have different bend pipes are widely used in these industries as gas-flow channels. Gas explosions usually occur in such regions and obviously have a negative impact on industrial safety [3]. Studies on the effect of different bend pipes on premixed methane-air explosion in pipes are helpful in the design and layout of gas-explosion-suppression systems in coal mines and play an important role in preventing gas explosions or effectively mitigating the damage.

Numerous theoretical studies have examined the propagation of gas explosion shock waves in pipes with different bend pipes. Yang and $\mathrm{Li}[4,5]$ established a mathematical model of bending based on the propagation laws of shock waves by means of a theoretical derivation. Zhou [6] analyzed the formation mechanism and propagation characteristics of impinging airflow with the theories of gas dynamics and fluid mechanics and obtained the relationships between the initial energy of impinging airflow in the turning and bifurcation roadway. Gao et al. [7] studied the propagation of the explosion wave and pointed out that the destruction of the gas explosion was mainly caused by the high pressure of high-speed airflow and shock waves. The results of the former are representative to some extent, but the influence of the mass force and wall friction is ignored in the derivation, and the models have certain limitations. In contrast, the latter 
has mainly been used to determine the head loss of liquids in agricultural machinery and petrochemical pipelines, but is not suitable for gas.

The propagation of gas explosion in different pipeline structures or with different obstacles has been studied extensively through experiments and numerical simulations [8-11]. Lin et al. [12-15] conducted a series of studies on the influence of obstacles, bifurcated pipes, single bend, U-shaped pipe and Z-shaped pipe, and T-shaped pipes in confined spaces on the shock wave and flame wave of a gas explosion. Yu et al. [16-19] studied the influences of the number, size, shape, and position of obstacles on the propagation of a blast wave by means of experiments and numerical simulations. Sun and Zheng $[20,21]$ qualitatively studied the effects of pipe diameters and sizes on the combustion and explosion characteristics of premixed gases using AutoGas software. Yin et al. [22] studied the propagation performance of a gasoline and air two-phase detonation wave in pipes with variable cross-sections through numerical simulations and found that the detonation wave produced an eddy current at the inflection point of the variable cross-section area and exhibited quenching. Jia et al. $[23,24]$ studied the gas exploration shock wave spread law via a one-way bifurcation pipeline and obtained computational formulas for the shock wave attenuation coefficients of branch pipelines and straight pipelines and the shock wave shunt coefficients of branch pipelines. Frolov et al. [25, 26] studied the deflagration to the detonation process in U-shaped structural pipes, while Zhu et al. $[27,28]$ found that the turning and bifurcation structures produce turbulence and studied the mechanism of flame acceleration. Obviously, the abovementioned studies have focused on the propagation characteristics of pressure waves according to built-in obstacles, bifurcated pipes, and pipes with different structures. However, there are few studies on the relationships between the attenuation rate of overpressure propagation, bending angle, and initial overpressure. The influence of the bending angle on gas explosion propagation and the peak overpressure attenuation coefficient is still unclear.

Therefore, the experimental explosion pipe system with a bend was established, and premixed methane-air explosion experiments were conducted. The overpressure propagation characteristics of three different premixed methane-air volumes and seven different bend pipes were studied experimentally. The aim was to determine the premixed methaneair explosion propagation laws in pipes with different bend pipes. The results can provide important theoretical guidelines for the prevention and control of gas explosions in different bend pipes.

\section{Experimental Study on Shock Wave of Gas Explosion via Different Bend Pipes}

In the premixed methane-air area, the spread of shock wave will be coupled with, and interact with, the combustion wave. In the area containing only air, the gas combustion finishes, and the shock wave decreases. According to the principles of explosion mechanics and hydromechanics, the propaga- tion of gas explosion pressure in a pipe varies according to the structure of the pipe. When the shock wave of gas explosion propagates through the bend points, the reflected wave will form. The purpose of this paper is to study the propagation characteristics and attenuation law of the shock wave with different bend pipes under different conditions.

2.1. Experimental System. The explosion experimental device is shown in Figure 1. The system components mainly include an explosion pipe system, air-gas distribution system, ignition system, and high-frequency data acquisition system. The explosion pipe system consists of a blasting chamber with a volume of $0.18 \mathrm{~m}^{3}$ and a pipe of diameter $180 \mathrm{~mm}$. The pipe is made of $16 \mathrm{Mn}$ steel, which has high temperature resistance, corrosion resistance, and pressure resistance up to $20 \mathrm{MPa}$.

The experimental pipe measures $17 \mathrm{~m}$ in length and consists of two parts, A and B. Part A is filled with a 9.5\% concentration of premixed methane-air combustible gas, and part $\mathrm{B}$ contains only air.

The air-gas distribution system is a key component of gas explosion experiments and mainly consists of a methane cylinder, vacuum pump, air compressor, circulating pump, vacuum meter, and regulating valve. The methane cylinder is filled with high-purity methane gas ( $99.99 \%$ purity). The vacuum pump (2XZ-2 rotary vane vacuum pump, Shanghai Hujing Industrial Pump Plant) is shown in Figure 2(a); this ensures the vacuum status of the blasting chamber. The air compressor (550-24 (1524) oil-free air compressor, Shanghai Jaguar Compressor Manufacturing Co., Ltd.) is shown in Figure 2(b). After each experiment, the air compressor conducts high-pressure ventilation of the explosion pipe network system for $30 \mathrm{~min}$ to discharge residual exhaust gas from the pipeline. The circulating pump shown in Figure 2(c) is operated for $20 \mathrm{~min}$ to ensure the uniform and sufficient mixing of methane. A precise vacuum manometer is used to control the methane and air inlets accurately. The principle of the gas distribution is to adopt Dalton's law of partial pressures. Dalton's law points out that the pressure of ideal gas mixture $\left(p_{\text {mix }}\right)$ is equal to the sum of the partial pressures $\left(p_{i}\right)$ of each component gas, namely,

$$
\begin{gathered}
p_{\text {mix }}=\sum_{i=1}^{n} p_{i}, \\
p_{i}=p_{\text {mix }} x_{i},
\end{gathered}
$$

where $p_{\text {mix }}$ is the total pressure of mixed gas, $p_{i}$ is the partial pressure of each component gas, and $x_{i}$ is the volume fraction of each component gas, $\%$.

According to Dalton's law of partial pressures, the partial pressure values of each component gas are calculated. Then, each gas component is filled into the device according to the value. After the gas preparation is completed, start the circulating pump, so as to ensure that the gas is mixed evenly and in a static state.

The ignition system is mainly composed of ignition electrodes, fuses, wires, and regulators, as shown in Figure 2(d). The ignition end remains closed when the other end is open. 


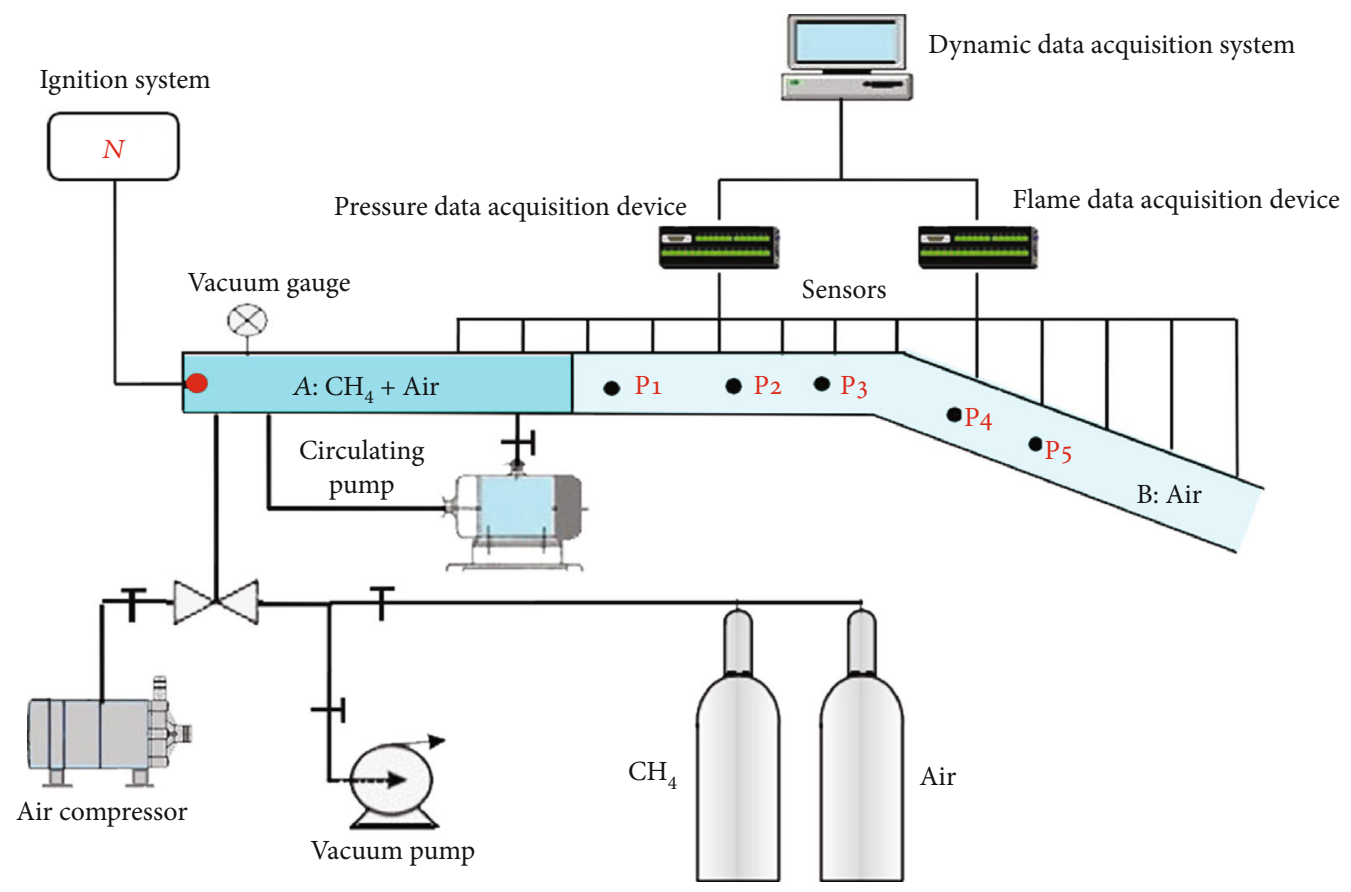

FIgURE 1: Gas explosion experimental device.

The ignition system is located at one end of the pipe and controls the ignition electrode in the middle of the flange plates at the front end of the pipe via the ignition device. Electric sparks generated by a $36 \mathrm{~V}$ direct current are used for ignition.

The high-frequency data acquisition system includes dynamic data acquisition units, pressure sensors, a controller for the flammable gas deflagration/detonation testing device, and a working host. The dynamic data acquisition unit (TST5206, see Figure 2(e)) has a sampling rate range of $0-$ $20 \mathrm{MSPS}$ and an accuracy of $0.1 \% \mathrm{FS}$. The pressure sensor model (CYG1401) has a measuring range of $0-3 \mathrm{MPa}$ and an accuracy of $0.5 \%$ FS. The signals acquired by the sensors are transmitted to the working host by a 32-way dynamic data acquisition unit. The controller of the flammable gas deflagration/detonation test device, which was developed by the Northeast University Safety Engineering Research Center, is shown in Figure 2(f). Its main functions are to display the vacuum degree of the pipeline, start and stop the vacuum pump, start and stop the circulating pump, and control the ignition device.

2.2. Experimental Scheme. When shock wave of gas explosion propagates at the bend, its propagation attenuation law is not only related to the change of bending angle but also related to initial overpressure of shock wave before bending. In the experiment, experimental devices of various bend pipes are built to study the relationships between the overpressure of explosion shock wave, bending angle, and initial overpressure before bending.

According to the bend characteristics of underground roadways in mines, seven bending angles, $30^{\circ}, 45^{\circ}, 60^{\circ}, 90^{\circ}$, $120^{\circ}, 135^{\circ}$, and $150^{\circ}$, are designed in the experiment. Figure 3 shows the experimental device diagrams of $30^{\circ}$, $60^{\circ}, 90^{\circ}$, and $135^{\circ}$ bend angles. As shown in Figure 4, six pressure sensors are arranged along the central line of the pipe. The equivalent distances of the measuring points from the explosion source are listed in Table 1 . The peak overpressures at measuring points $\mathrm{P} 1, \mathrm{P} 2, \cdots, \mathrm{P} 5$ are expressed as $\Delta p_{1}, \Delta p_{2}$, $\cdots, \Delta p_{5}$, respectively.

The main steps in the gas explosion experiments are the installation and debugging of the pipeline system, gas tightness test, gas distribution and charging, circulation mixing, ignition, and data acquisition. In the experiments, the temperature is $298 \mathrm{~K}$, and atmospheric pressure is $101.325 \mathrm{kPa}$.

This paper derives the propagation and attenuation law of shock wave after gas explosion accident in general air districts, so the concept of the overpressure is that the absolute pressure of shock wave removes the standard atmospheric pressure, which is a parameter characterizing shock wave propagation. The shock wave overpressure is measured in Pascals. The experiments mainly focus on shock wave attenuation laws under different initial overpressures and distinct bend pipes. Therefore, $0.23 \mathrm{~m}^{3}, 0.28 \mathrm{~m}^{3}$, and $0.31 \mathrm{~m}^{3}$ of combustible gas are added to the pipe at a $9.5 \%$ concentration under the same bent configuration to change initial peak overpressure of shock wave. Three tests are conducted for each experimental condition, and the mean value is taken as the result for that configuration, and a total of 21 successful experiments are required.

\subsection{Experimental Results and Analysis}

2.3.1. Characteristics of Shock Wave Propagation via Bend Pipes. Figure 5 shows the overpressure-time variation curves of measuring points $\mathrm{P} 1, \mathrm{P} 2, \mathrm{P} 3, \mathrm{P} 4$, and $\mathrm{P} 5$ under $60^{\circ}$ bend angle and $0.28 \mathrm{~m}^{3}$ gas volume. $\mathrm{P} 3$ has a peak overpressure at $0.047 \mathrm{~s}$ before bending. After the shock wave propagates for 


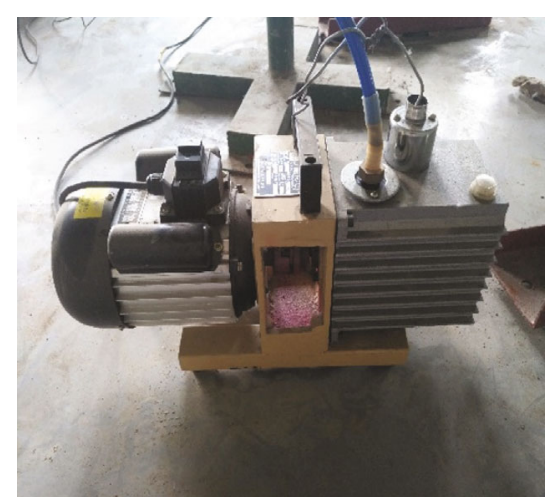

(a)

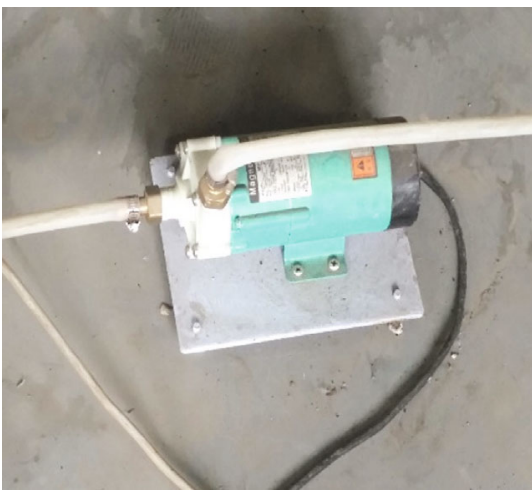

(c)

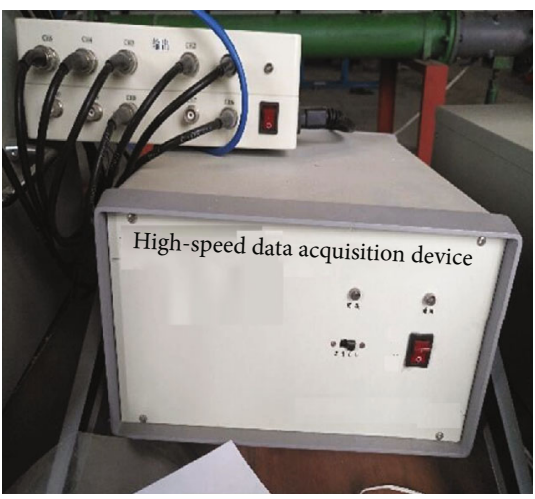

(e)

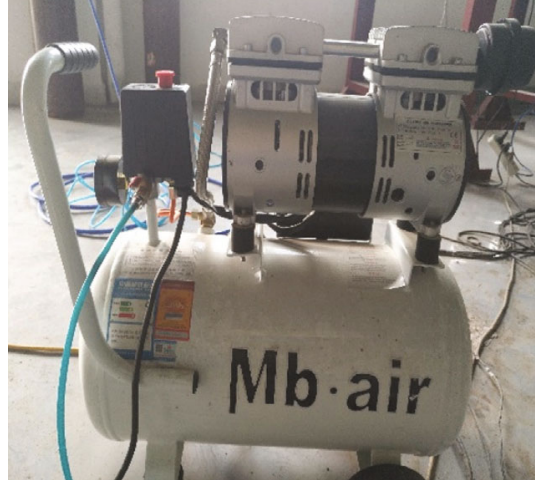

(b)

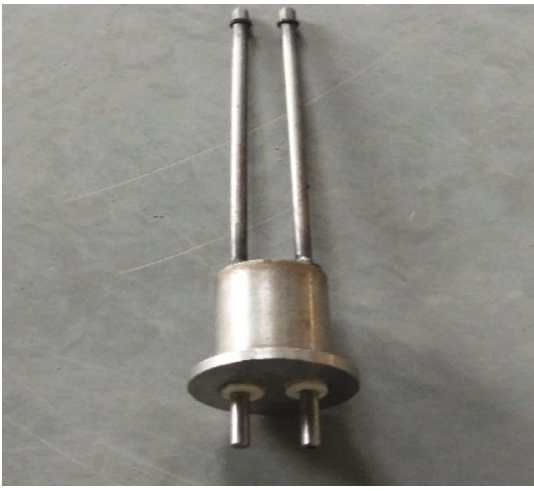

(d)

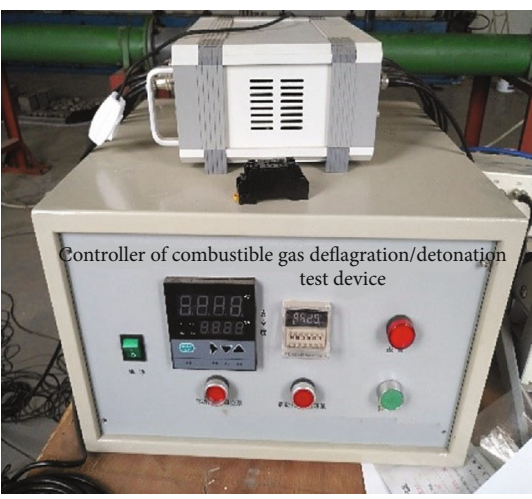

(f)

Figure 2: Main equipment of gas explosion experiment system: (a) vacuum pump, (b) air compressor, (c) circulating pump, (d) ignition electrode, (e) high-speed data acquisition device, and (f) gas explosion device controller.

a certain distance, another peak overpressure appears. It can be seen that explosion shock wave reflects at the corner, and the reflected shock wave propagates backwards, which shows that the bend structure has a certain influence on the reflection of explosion shock wave.

According to the propagation process of explosion shock wave, the peak overpressure of measuring point P1 is $0.4749 \mathrm{MPa}$. With the increase of propagation distance, the peak overpressure at P2 increases to $0.9833 \mathrm{MPa}$; then, the peak overpressure at $\mathrm{P} 5$ decreases to $0.3732 \mathrm{MPa}$. The peak overpressure of explosion shock wave presents a rising and then descending trend, and other operating conditions show the same change trend. In addition, negative pressure occurs at the outlet of the pipe (measuring point $\mathrm{P} 5$ ).
Peak overpressure at $\mathrm{P} 3$ is $0.7162 \mathrm{MPa}$, and that at $\mathrm{P} 4$ is $0.5552 \mathrm{MPa}$. After the $60^{\circ}$ bend angle, the peak overpressure attenuates by $22.48 \%$. Compared with $30^{\circ}$ and $150^{\circ}$ bend angles, the peak overpressure attenuates by $12.73 \%$ and $51.29 \%$ under the same gas volume, respectively, which means that attenuation amplitude of peak overpressure is different with different bend angles. In addition, the initial overpressure before bending also has certain influence on the attenuation of shock wave. For the $60^{\circ}$ bend angle, when the initial pressure before bending is $0.6026 \mathrm{MPa}$ and $0.8245 \mathrm{MPa}$, respectively, the peak overpressure attenuates by $18.86 \%$ and $21.86 \%$, respectively. It can be seen that attenuation amplitude of peak overpressure varies with initial overpressure before bending. 


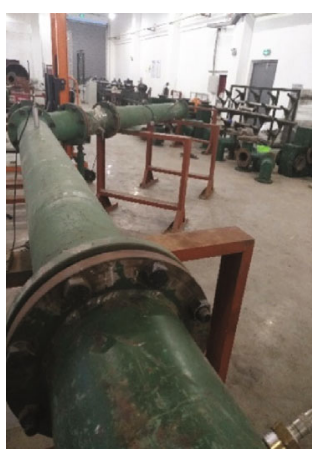

(a)

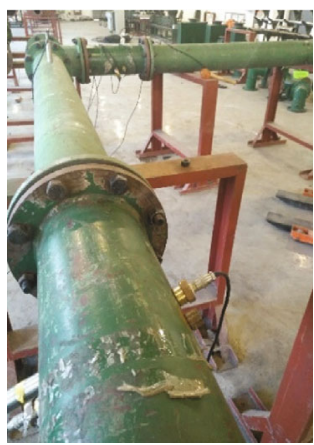

(c)

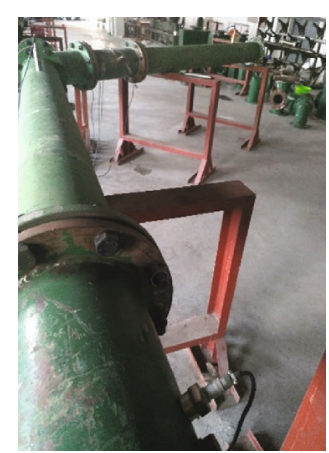

(b)

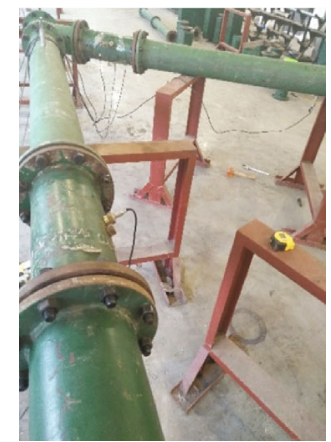

(d)

Figure 3: Gas explosion test devices of bend pipes: (a) $30^{\circ}$, (b) $60^{\circ}$, (c) $90^{\circ}$, and (d) $135^{\circ}$.

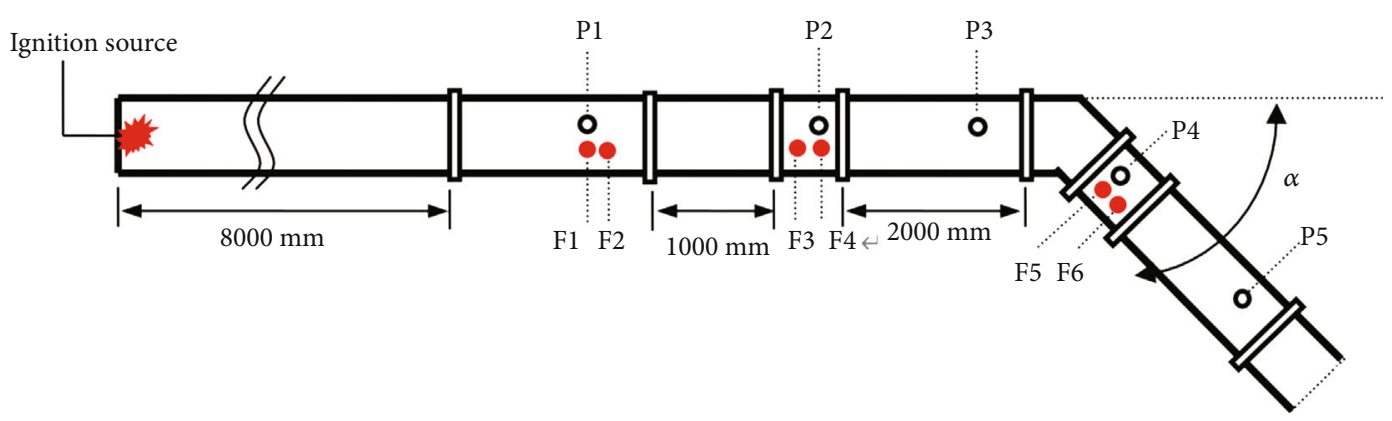

FIgURE 4: Sketch map of the bend pipe.

TABle 1: Distance of each measuring point from the explosion source in bend pipe $(\mathrm{m})$.

\begin{tabular}{lccccc}
\hline Measuring point & P1 & P2 & P3 & P4 & P5 \\
\hline Distance & 9.5 & 11.3 & 13 & 14.25 & 16 \\
\hline
\end{tabular}

Note: $P$ represents the pressure sensor.

Due to the influence of local resistance at the bend, the total energy decreases, and the change of the pipe direction accelerates the attenuation of shock wave. It can be seen that propagation attenuation of gas explosion in bend pipes is mainly affected by the bend angle and initial overpressure before bending. Table 2 shows experimental peak overpressures of gas explosion at each measuring point when gas volume is $0.23 \mathrm{~m}^{3}, 0.28 \mathrm{~m}^{3}$, and $0.31 \mathrm{~m}^{3}$, respectively, in different bend angles.
2.3.2. Attenuation Characteristics of Explosion Shock Wave in Different Bend Pipes. The attenuation degree of explosion shock wave at the bend is described by the attenuation coefficient, which is equal to the ratio of peak overpressure before bending $\left(\Delta p_{3}\right)$ and peak overpressure after bending $\left(\Delta p_{4}\right)$. The attenuation coefficient of peak overpressure at the bend is determined by the following formula, namely,

$$
k=\frac{\Delta p_{3}}{\Delta p_{4}}
$$

According to equation (2), the attenuation coefficient of explosion shock wave at each bend is calculated as shown in Table 3. It can be seen from the table that peak overpressure of gas explosion has an obvious downward trend at the bend, and the downward range increases obviously with the increase of angle. The peak overpressure 


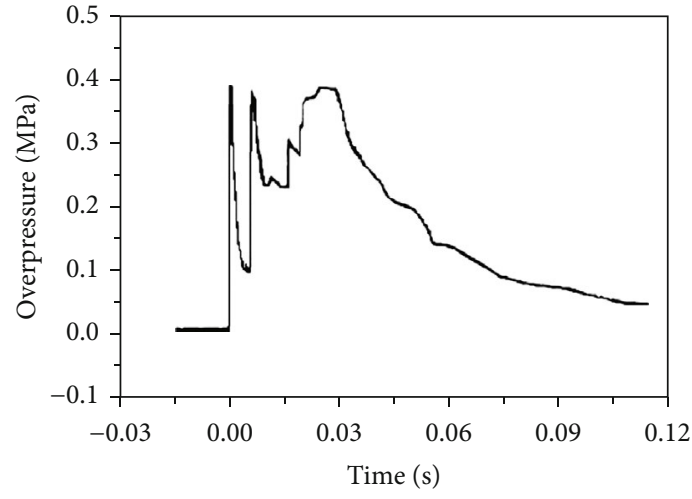

$-\mathrm{P} 1$

(a)

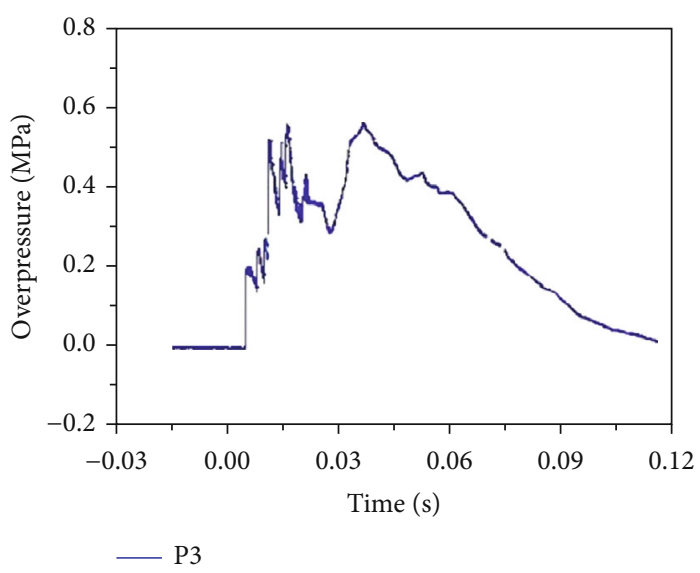

(c)

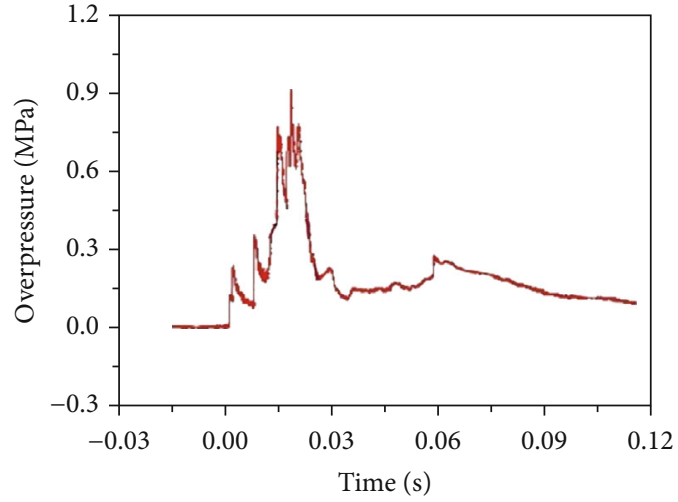

$-\mathrm{P} 2$

(b)

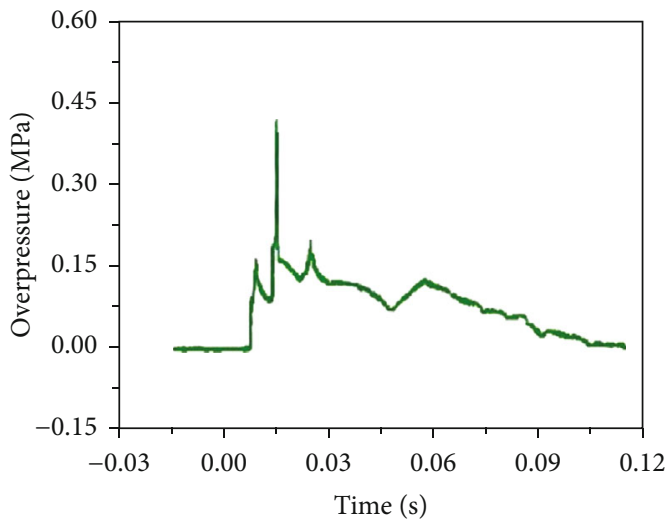

- P4

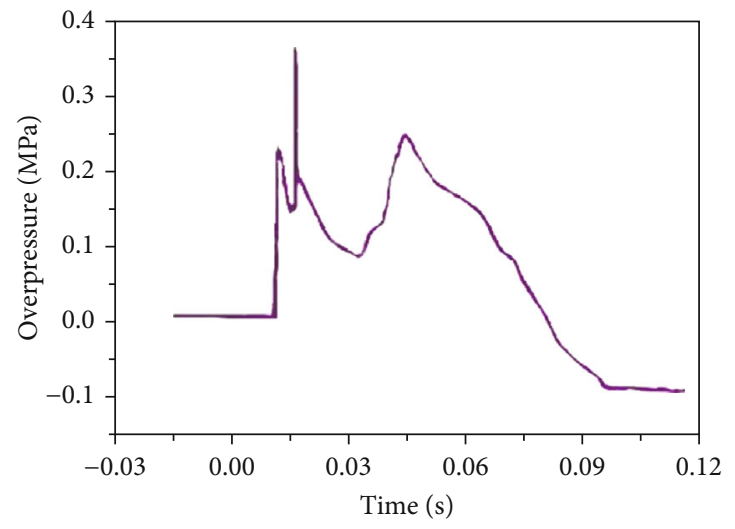

- P5

(e)

Figure 5: Overpressure-time curve of gas explosion $\left(\alpha=60^{\circ}, V=0.28 \mathrm{~m}^{3}\right)$.

before bending also has certain influence on the attenuation coefficient; that is, it increases with the increase of initial peak overpressure.

As can be seen from Table 3 and Figure 6, due to the different reflection effects of bend pipes, peak overpressures of gas explosion are different before and after bending. For the pipes with the same bend angles, initial peak overpressure before bending and peak overpressure after bending both increases with the increase of gas volume. With the increase of bending angle, the attenuation coefficient of explosion shock wave gradually increases. For the same bend angle, the attenuation coefficient of explosion shock wave increases with the increase of gas volume, but the increase is small. From $30^{\circ}$ to $90^{\circ}$, the average value of the attenuation coefficient increases from 1.130 to 1.354 , and the increase amplitude is relatively gentle. From $90^{\circ}$ to $150^{\circ}$, the average value of the attenuation coefficient increases from 1.354 to 2.046, with a steep increase. 
TABLE 2: Experimental peak overpressure of gas explosion and distance in bend pipes.

\begin{tabular}{|c|c|c|c|c|c|c|}
\hline \multirow{2}{*}{$\begin{array}{l}\text { Bending } \\
\text { angle }\left(^{\circ}\right)\end{array}$} & \multirow{2}{*}{$\begin{array}{c}\text { Gas } \\
\text { volume } \\
\left(\mathrm{m}^{3}\right)\end{array}$} & \multicolumn{5}{|c|}{$\begin{array}{c}\text { Experimental peak overpressure }(\mathrm{MPa}) \\
\text { Distance from ignition source }(\mathrm{m})\end{array}$} \\
\hline & & 9.5 & 11.3 & 13 & 14.25 & 16 \\
\hline \multirow{3}{*}{30} & 0.23 & 0.5994 & 0.8862 & 0.7180 & 0.6571 & 0.5629 \\
\hline & 0.28 & 0.4007 & 0.9213 & 0.7675 & 0.6698 & 0.5162 \\
\hline & 0.31 & 0.6142 & 1.0245 & 0.7854 & 0.6812 & 0.5841 \\
\hline \multirow{3}{*}{45} & 0.23 & 0.5283 & 0.8648 & 0.5581 & 0.4718 & 0.4054 \\
\hline & 0.28 & 0.4368 & 0.9432 & 0.7087 & 0.5955 & 0.3563 \\
\hline & 0.31 & 0.4854 & 0.9784 & 0.7758 & 0.6456 & 0.4512 \\
\hline \multirow{3}{*}{60} & 0.23 & 0.5490 & 0.7775 & 0.6026 & 0.4889 & 0.3981 \\
\hline & 0.28 & 0.4749 & 0.9833 & 0.7162 & 0.5552 & 0.3732 \\
\hline & 0.31 & 0.6054 & 1.1450 & 0.8245 & 0.6442 & 0.4523 \\
\hline \multirow{3}{*}{90} & 0.23 & 0.3618 & 0.7084 & 0.5110 & 0.3889 & 0.3114 \\
\hline & 0.28 & 0.5299 & 0.8252 & 0.7231 & 0.5320 & 0.2802 \\
\hline & 0.31 & 0.5124 & 0.8654 & 0.7842 & 0.5645 & 0.3512 \\
\hline \multirow{3}{*}{120} & 0.23 & 0.4593 & 0.8786 & 0.5355 & 0.3498 & 0.3320 \\
\hline & 0.28 & 0.4997 & 0.7467 & 0.6888 & 0.4339 & 0.3957 \\
\hline & 0.31 & 0.5654 & 1.0874 & 0.7542 & 0.4642 & 0.4245 \\
\hline \multirow{3}{*}{135} & 0.23 & 0.3125 & 0.7307 & 0.6127 & 0.3430 & 0.3261 \\
\hline & 0.28 & 0.4986 & 0.8318 & 0.6491 & 0.3539 & 0.2734 \\
\hline & 0.31 & 0.5482 & 0.9654 & 0.8452 & 0.4553 & 0.4242 \\
\hline \multirow{3}{*}{150} & 0.23 & 0.4139 & 0.9101 & 0.7999 & 0.3971 & 0.2900 \\
\hline & 0.28 & 0.6001 & 0.9642 & 0.8592 & 0.4185 & 0.3534 \\
\hline & 0.31 & 0.5421 & 1.1689 & 0.8745 & 0.4225 & 0.4123 \\
\hline
\end{tabular}

2.3.3. Coupling Relationships between Attenuation Coefficient, Initial Peak Overpressure, and Bending Angle. In order to further explore the relationships between the attenuation coefficient of peak overpressure, bending angle, and initial peak overpressure at the bend, the coupling relationships between them are established based on a large number of experimental data.

Assuming that the functional relation between attenuation coefficient $k$, initial peak overpressure $\Delta p_{3}$, and bending angle $\alpha$ can be obtained:

$$
k=A \cdot\left(\Delta p_{3}\right)^{B} \cdot \alpha^{C},
$$

where $A, B$, and $C$ are the unsolved coefficients and exponentials of the nonlinear model.

Taking the natural logarithm of both sides of equation (2), we can get the following result:

$$
\ln (k)=\ln A+B \ln \left(\Delta p_{3}\right)+C \ln (\alpha) .
$$

According to the experimental parameters and result data in Table 3, equation (4) is used as the mathematical model between the attenuation coefficient of peak overpressure, initial peak overpressure, and bending angle. Using the MATLAB software for multiple nonlinear regression,
TABLE 3: Peak overpressure and attenuation coefficient of explosion

\begin{tabular}{|c|c|c|c|c|c|}
\hline $\begin{array}{l}\text { Bending } \\
\text { angle } \alpha\left(^{\circ}\right)\end{array}$ & $\begin{array}{c}\text { Gas } \\
\text { volume } \\
\left(\mathrm{m}^{3}\right)\end{array}$ & $\begin{array}{c}\Delta p_{3} \\
(\mathrm{MPa})\end{array}$ & $\begin{array}{c}\Delta p_{4} \\
(\mathrm{MPa})\end{array}$ & $\begin{array}{l}\text { Attenuation } \\
\text { coefficient } k\end{array}$ & $\begin{array}{l}\text { Average } \\
\text { value } \bar{k}\end{array}$ \\
\hline \multirow{3}{*}{30} & 0.23 & 0.7180 & 0.6571 & 1.093 & \multirow{3}{*}{1.130} \\
\hline & 0.28 & 0.7675 & 0.6698 & 1.146 & \\
\hline & 0.31 & 0.7854 & 0.6812 & 1.153 & \\
\hline \multirow{3}{*}{45} & 0.23 & 0.5581 & 0.4718 & 1.183 & \multirow{3}{*}{1.192} \\
\hline & 0.28 & 0.7087 & 0.5955 & 1.190 & \\
\hline & 0.31 & 0.7758 & 0.6456 & 1.202 & \\
\hline \multirow{3}{*}{60} & 0.23 & 0.6026 & 0.4889 & 1.233 & \multirow{3}{*}{1.267} \\
\hline & 0.28 & 0.7162 & 0.5552 & 1.290 & \\
\hline & 0.31 & 0.8245 & 0.6442 & 1.280 & \\
\hline \multirow{3}{*}{90} & 0.23 & 0.5110 & 0.3889 & 1.314 & \multirow{3}{*}{1.354} \\
\hline & 0.28 & 0.7231 & 0.5320 & 1.359 & \\
\hline & 0.31 & 0.7842 & 0.5645 & 1.389 & \\
\hline \multirow{3}{*}{120} & 0.23 & 0.5355 & 0.3498 & 1.531 & \multirow{3}{*}{1.581} \\
\hline & 0.28 & 0.6888 & 0.4339 & 1.588 & \\
\hline & 0.31 & 0.7542 & 0.4642 & 1.625 & \\
\hline \multirow{3}{*}{135} & 0.23 & 0.6127 & 0.3430 & 1.786 & \multirow{3}{*}{1.826} \\
\hline & 0.28 & 0.6491 & 0.3539 & 1.834 & \\
\hline & 0.31 & 0.8452 & 0.4553 & 1.856 & \\
\hline \multirow{3}{*}{150} & 0.23 & 0.7999 & 0.3971 & 2.015 & \multirow{3}{*}{2.046} \\
\hline & 0.28 & 0.8592 & 0.4185 & 2.053 & \\
\hline & 0.31 & 0.8745 & 0.4225 & 2.070 & \\
\hline
\end{tabular}
shock wave in bend pipes.

the fitting coefficients are obtained: $A=0.326, B=0.341$, and $C=0.369$. By substituting above coefficients and indexes into equation (4), the attenuation coefficient $k$ can be described as

$$
K=0.326\left(\Delta p_{4}\right)^{0.341} \alpha^{0.369} .
$$

Figure 7 shows the comparison curves between the experiment value and model fitting value of the attenuation coefficient. It can be seen from the curve that the relative error between the experimental value and model fitting value is within $\pm 10 \%$. Therefore, equation (5) can be used as a formula to solve the ventilation network in the later catastrophic process.

\section{Numerical Simulations of Gas Explosion Shock Waves via Different Bend Pipes}

Using the FLUENT software, the shock wave overpressure of gas explosion spread law in pipes with different bend pipes was investigated numerically. The experimental results were incorporated into the numerical simulations, and mathematical models were established under the experimental conditions. The attenuation degree of shock wave overpressure at different angles was analyzed, and the attenuation formula obtained from the experiment in Section 2 was verified. 


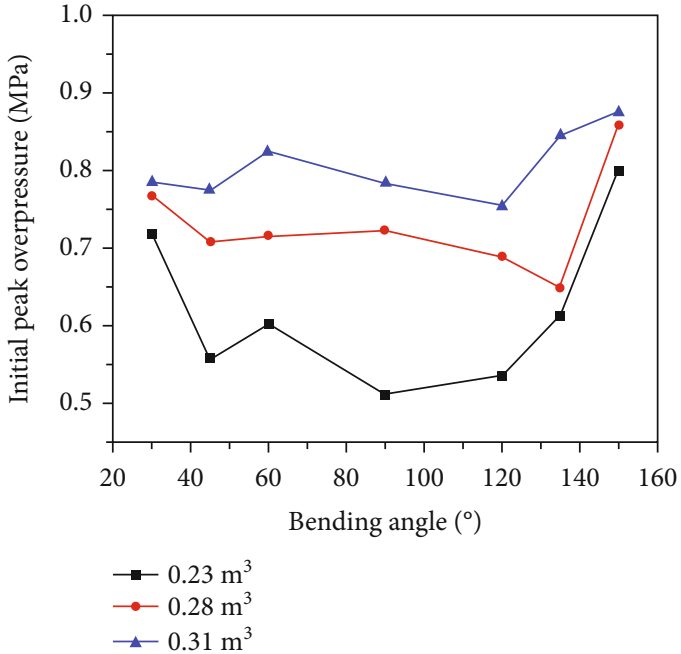

(a)

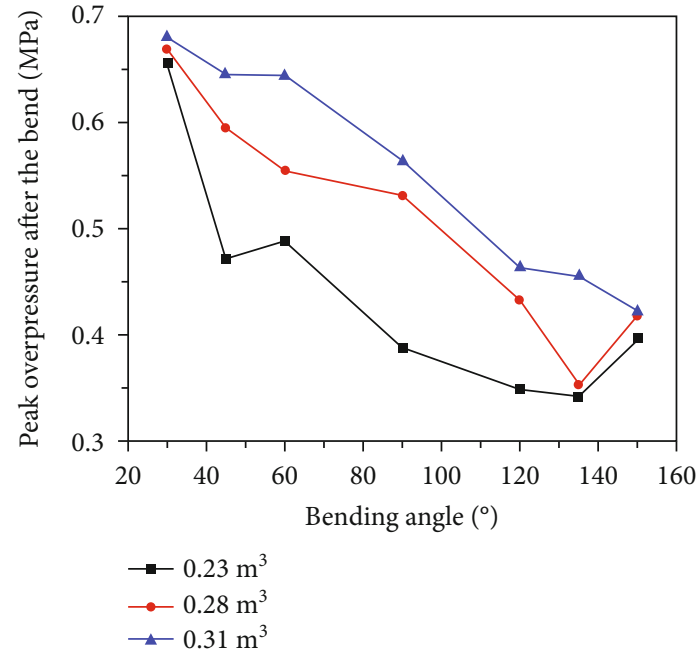

(b)

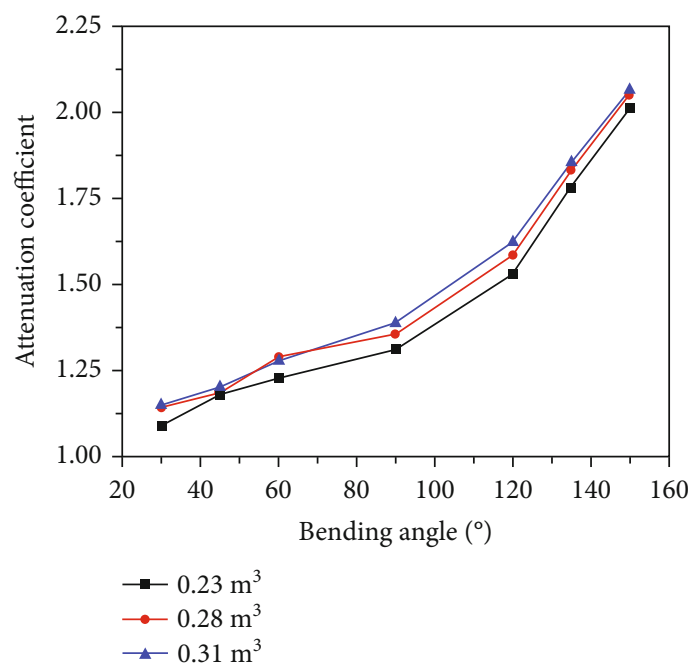

(c)

FIGURE 6: Relationships between initial peak overpressure, peak overpressure after the bend, attenuation coefficient, and bending angle.

3.1. Numerical Models and Simulation Methods. In a mathematical simulation, the gas explosion process can generally be treated as the thermal expansion process of an ideal gas, and the gas dynamics can be captured by the equations of mass conservation, momentum conservation, energy conservation, and component equilibrium equations [29]. Generally, the Reynolds-averaged Navier-Stokes equations are used as the governing equations [30,31]. The main equations are as follows:

$$
\begin{gathered}
\frac{\partial \rho}{\partial t}+\frac{\partial(\rho u)}{\partial x}=0 \\
\frac{\partial \rho u}{\partial t}+\frac{\partial(\rho u u)}{\partial x}=-\frac{\partial p}{\partial x}+\frac{4}{3} \mu_{e} \frac{\partial u}{\partial x} \\
\frac{\partial \rho h}{\partial t}+\frac{\partial}{\partial x}\left[\rho u h-\frac{\mu_{e}}{\sigma_{h}} \frac{\partial h}{\partial x}\right]=\frac{D p}{D t}+S_{h} \\
\frac{\partial}{\partial t}\left(\rho Y_{\mathrm{fu}}\right)+\frac{\partial}{\partial x}\left[\rho u Y_{\mathrm{fu}}-\frac{\mu_{e}}{\sigma_{\mathrm{fu}}} \frac{\partial Y_{f u}}{\partial x}\right]=R_{\mathrm{fu}}
\end{gathered}
$$

where $\rho$ is the density, $P$ is the static pressure, $u$ is the particle velocity, $\mu_{e}$ is the dynamic viscous coefficient, $h$ is the enthalpy, $Y_{f u}$ is the fuel mass fraction, $R_{f u}$ is the rate for volume combustion, $k$ is the turbulent kinetic energy, and $S_{h}$ is the heat source term.

Turbulence is an important factor in explosive gas combustion. Using the $k-\varepsilon$ turbulence model, the turbulent kinetic energy equation and the turbulent kinetic dissipation rate equation are as follows [32]:

$$
\begin{gathered}
\frac{\partial}{\partial t}(\rho k)+\frac{\partial}{\partial x_{j}}\left[\rho u_{j} k-\frac{\mu_{e}}{\sigma_{k}} \frac{\partial k}{\partial x_{j}}\right]=G-\rho \varepsilon \\
\frac{\partial}{\partial t}(\rho k)+\frac{\partial}{\partial x_{j}}\left[\rho u_{j} \varepsilon-\frac{\mu_{e}}{\sigma_{k}} \frac{\partial \varepsilon}{\partial x_{j}}\right]=C_{1} G \frac{\varepsilon}{k}-C_{2} \rho \frac{\varepsilon^{2}}{k}
\end{gathered}
$$

where $\mu_{e}=\mu_{l}+\mu_{t}$ is the effective viscous coefficient; $\mu_{l}$ is the laminar viscous coefficient; $\mu_{t}=C_{\mu} \rho k^{2} / \varepsilon$ is the turbulent 


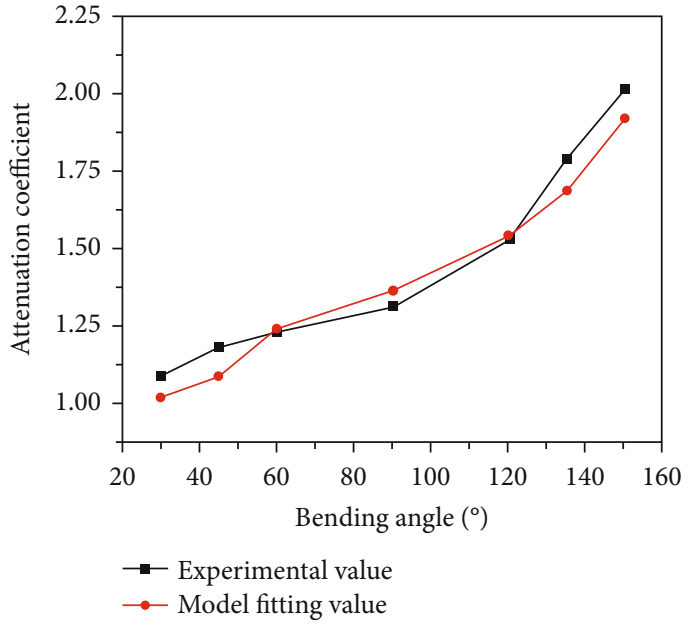

(a)

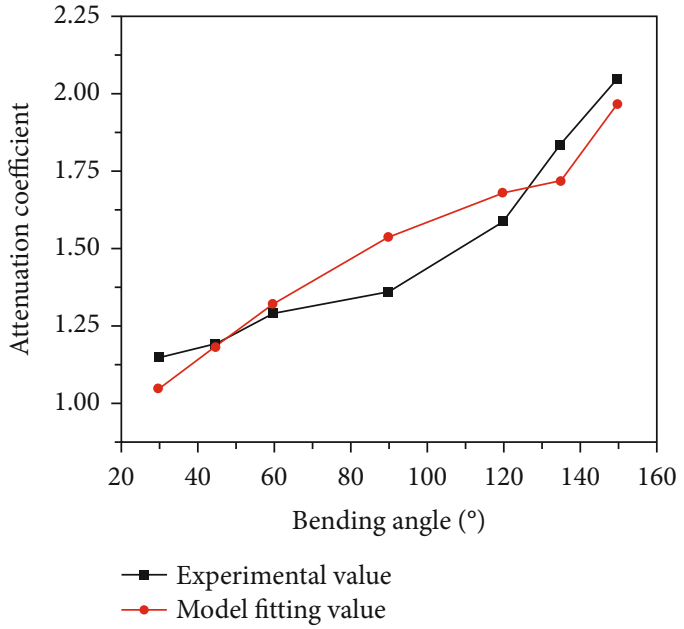

(b)

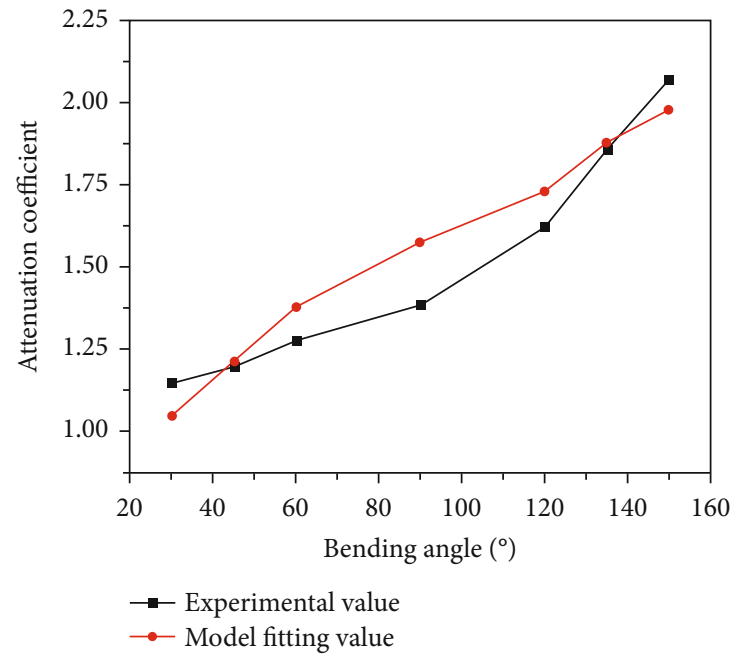

(c)

FIGURE 7: Comparisons of the experimental value and model fitting value of attenuation coefficient: (a) $0.23 \mathrm{~m}^{3}$ gas volume, (b) $0.28 \mathrm{~m}^{3}$ gas volume, and (c) $0.31 \mathrm{~m}^{3}$ gas volume.

viscous coefficient; $\delta_{i j}$ is the Kronecker operator; $C_{\mu}, C_{1}, C_{2}$, $\sigma_{k}$, and $\sigma_{\varepsilon}$ are the turbulent model constants, respectively; and $G$ is obtained as follows:

$$
G=\frac{\partial u_{i}}{\partial x_{j}}\left[\mu_{e}\left(\frac{\partial u_{i}}{\partial x_{j}}+\frac{\partial u_{j}}{\partial x_{i}}\right)-\frac{2}{3} \delta_{i j}\left(\rho k+\mu_{e} \frac{\partial u_{k}}{\partial x_{k}}\right)\right]
$$

The explosion of combustible gases is a turbulent combustion process accompanied by complex chemical reactions. It is necessary to consider both turbulent effects and chemical reaction dynamics. Therefore, the EBU-Arrhenius combustion model is adopted [33]. The turbulent flame velocity is usually calculated by the flame front model, and the turbulent flame velocity $U_{t}$ is given by

$$
U_{t}=A\left(u^{\prime}\right)^{3 / 4} U_{l}^{1 / 2} \alpha^{-1 / 4} l_{t}^{1 / 4} \cdot g=A u^{\prime}\left(\frac{\tau_{l}}{\tau_{c}}\right)^{1 / 4} \cdot g
$$

The turbulence intensity $u^{\prime}$ and turbulence characteristic scale $l_{t}$ are calculated as follows:

$$
u^{\prime}=\sqrt{2 / 3 k}, l_{t}=C_{D}\left(\left(u^{\prime}\right)^{3} / \varepsilon\right),(14)
$$

where $A$ is the model constant, usually $0.52, U_{l}$ is the laminar flame velocity $[\mathrm{m} / \mathrm{s}], \alpha=k / \rho c_{p}$ is the heat transfer coefficient of temperature $[\mathrm{m} 2 / \mathrm{s}], \tau_{l}=l_{t} / u^{\prime}$ is the turbulence time scale, $\tau_{c}=\alpha / U_{l}^{2}$ is the time scale of the chemical reaction, $g$ is the flame stretching factor (when there is no stretching, $g=1$ ), and $C_{D}$ is a constant, usually 0.37 .

In the numerical simulations, the finite volume method is adopted. The SIMPLEC algorithm [34] for pressure-velocity coupling is selected, and the subrelaxation method is adopted to control the convergence rate.

3.2. Analysis of Shock Wave Overpressure Propagation in Pipes. In order to verify the experimental results, seven geometric models of bend pipes are established in total, including $30^{\circ}, 45^{\circ}, 60^{\circ}, 90^{\circ}, 120^{\circ}, 135^{\circ}$, and $150^{\circ}$. The size of the pipe is exactly the same as the experimental system. The pipe 

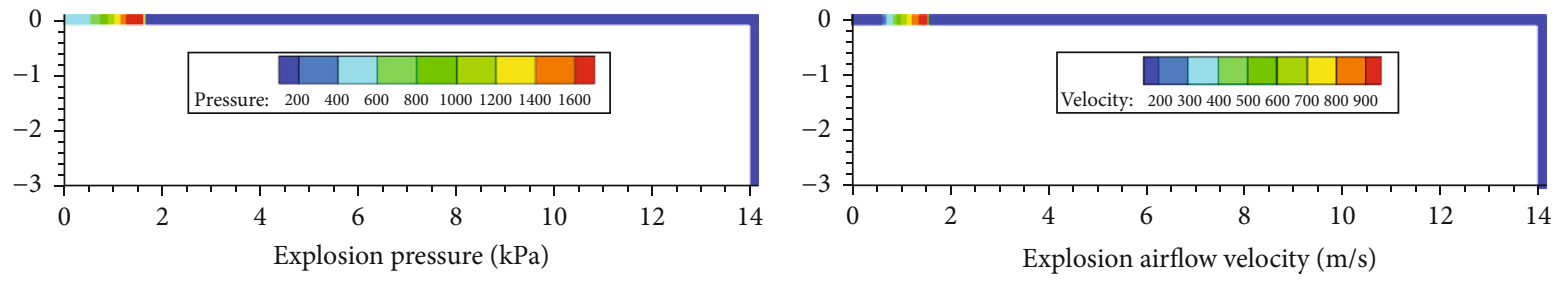

(a)
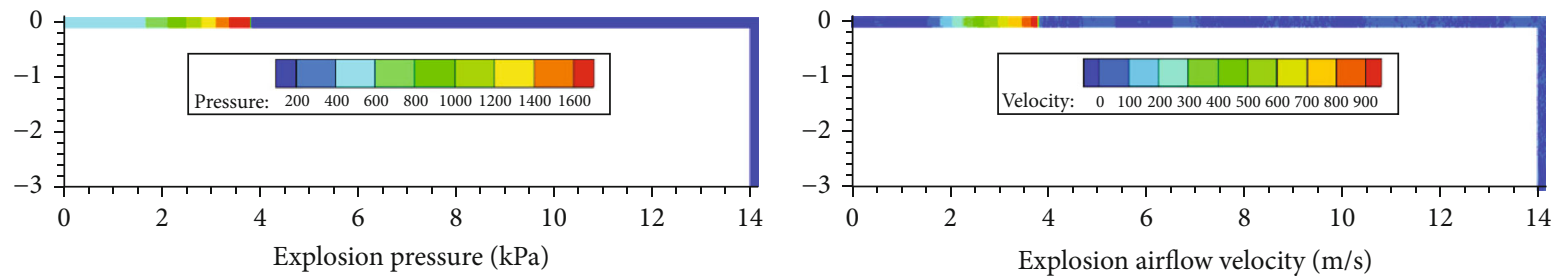

(b)
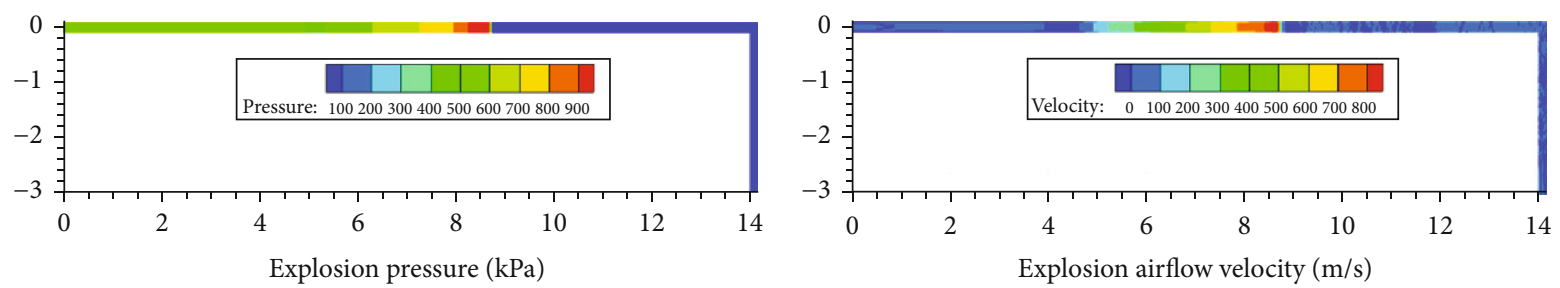

(c)
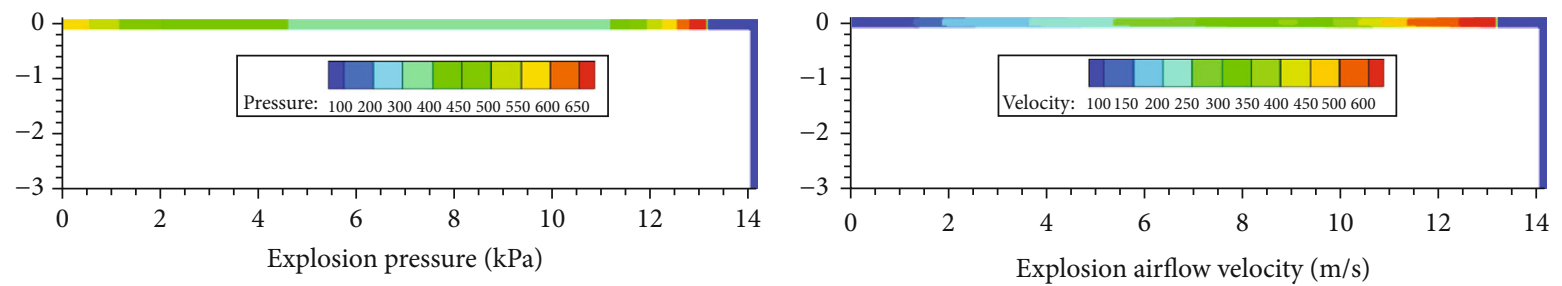

(d)
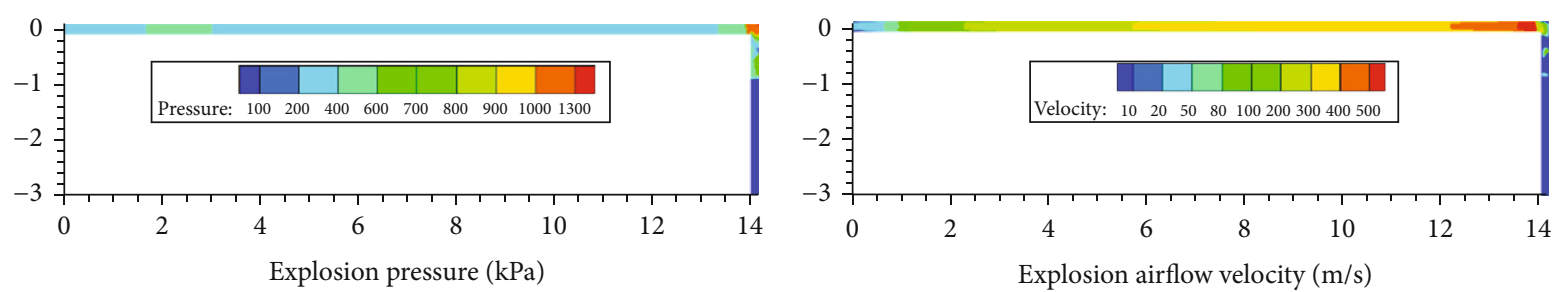

(e)
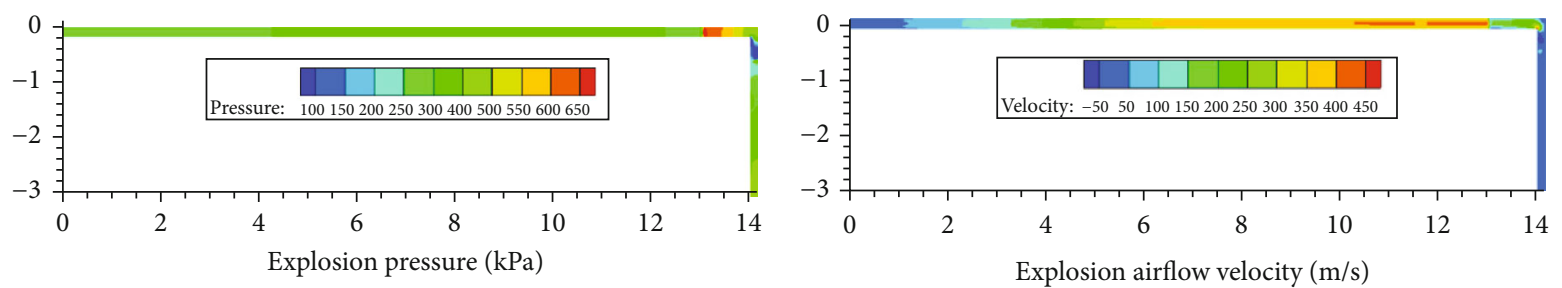

(f)

FIGURE 8: Simulation diagrams of explosion pressure and airflow velocity at different times of the bend pipe $\left(V=0.23 \mathrm{~m}^{3}, \alpha=90^{\circ}\right):(\mathrm{a}) t=$ $0.8 \mathrm{~ms}$, (b) $t=2.0 \mathrm{~ms}$, (c) $t=5.4 \mathrm{~ms}$, (d) $t=9.8 \mathrm{~ms}$, (e) $t=12 \mathrm{~ms}$, and (f) $t=15.1 \mathrm{~ms}$.

is closed at one end and open at the other end. Within the range of $x \mathrm{~m}(x=8 \mathrm{~m}, 10 \mathrm{~m}$, and $11 \mathrm{~m})$ at the closed end, it is filled with premixed methane-air combustible gas with a concentration of $9.5 \%$; that is, the gas volume is $0.23 \mathrm{~m}^{3}$, $0.28 \mathrm{~m}^{3}$, and $0.31 \mathrm{~m}^{3}$, respectively. The ignition source is at the closed end, and initial ignition temperature is $1400 \mathrm{~K}$. 


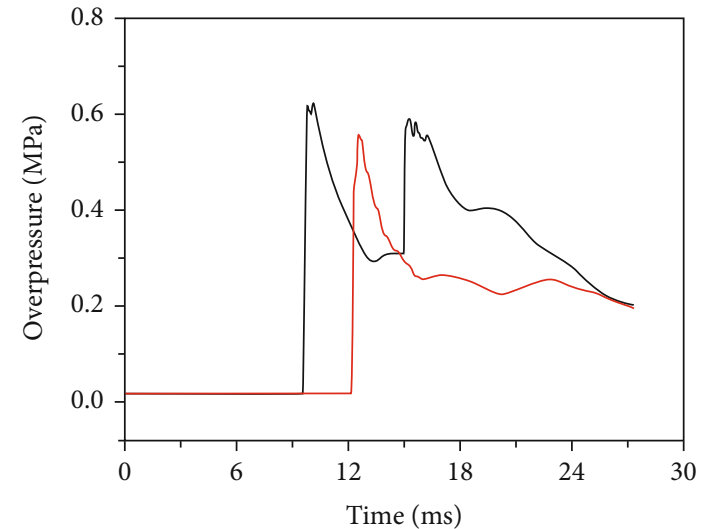

$-\mathrm{A}$

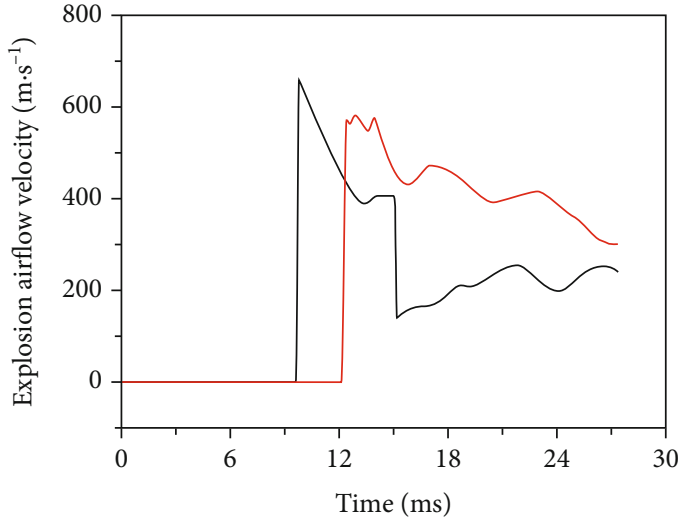

$-\mathrm{A}$

(a)

(b)

FIGURE 9: Relationships between the overpressure and airflow velocity at different moments before and after the bend $\left(V=0.23 \mathrm{~m}^{3}, \alpha=90^{\circ}\right)$.
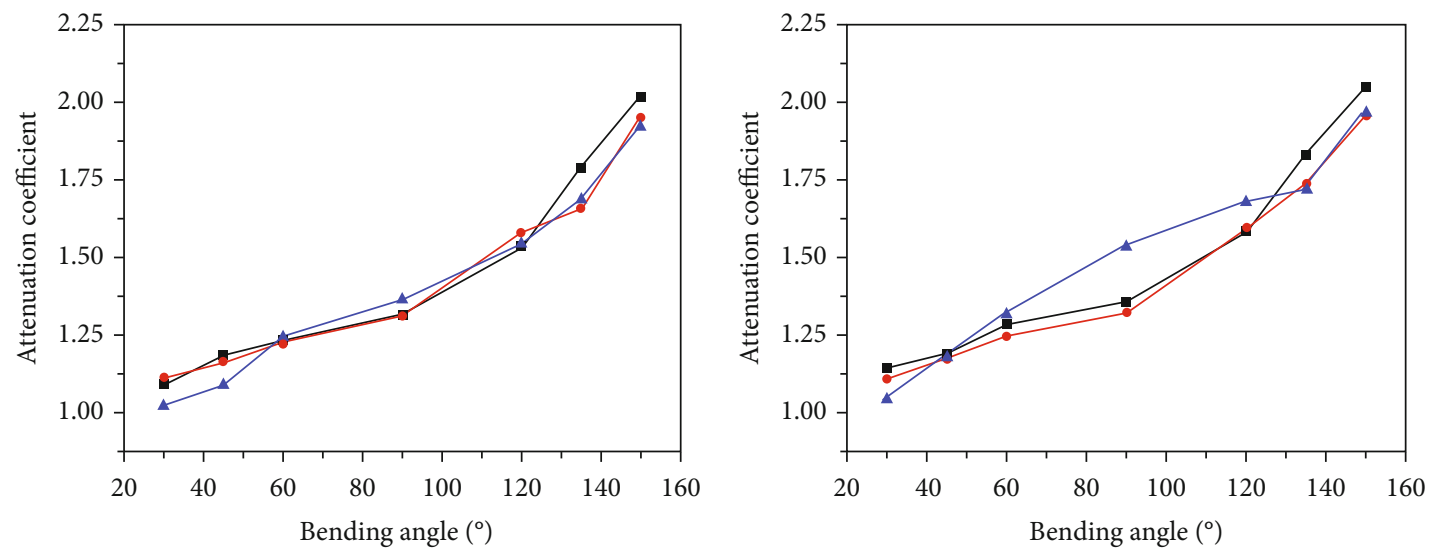

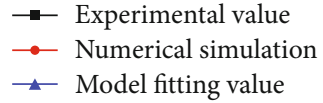

(a)
- Experimental value

$\rightarrow$ Numerical simulation

$\rightarrow$ Model fitting value

(b)

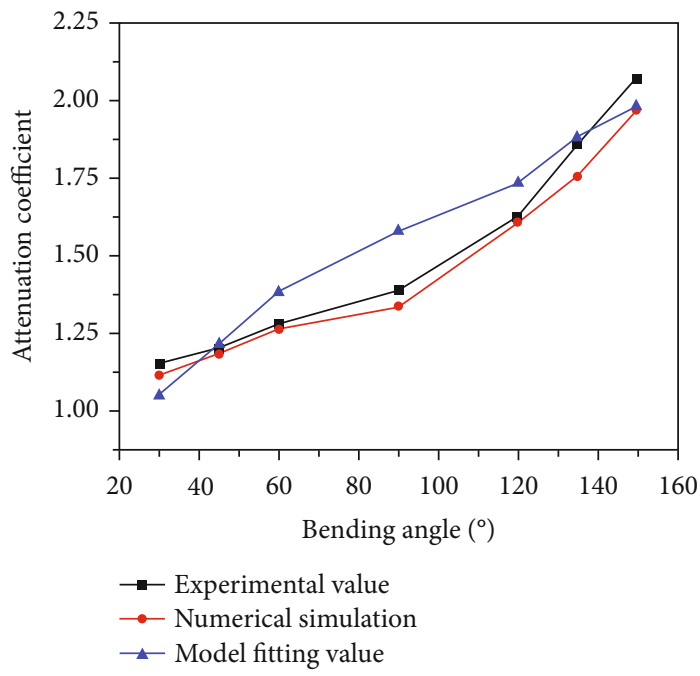

(c)

Figure 10: Comparison of numerical simulation, experimental results, and model fitting values of the attenuation coefficient: (a) $0.23 \mathrm{~m}^{3}$ gas volume, (b) $0.28 \mathrm{~m}^{3}$ gas volume, and (c) $0.31 \mathrm{~m}^{3}$ gas volume. 
TABLE 4: Comparison of simulated and experimental results.

\begin{tabular}{|c|c|c|c|c|c|c|}
\hline \multirow{2}{*}{ Bending angle $\left({ }^{\circ}\right)$} & \multirow{2}{*}{ Gas volume $\left(\mathrm{m}^{3}\right)$} & \multirow{2}{*}{$\Delta p_{\mathrm{A}}(\mathrm{MPa})$} & \multirow{2}{*}{$\Delta p_{\mathrm{B}}(\mathrm{MPa})$} & \multicolumn{2}{|c|}{ Attenuation coefficient } & \multirow{2}{*}{ Relative error $E(\%)$} \\
\hline & & & & Simulated results & Experimental results & \\
\hline \multirow{3}{*}{30} & 0.23 & 0.6132 & 0.5526 & 1.110 & 1.093 & 1.57 \\
\hline & 0.28 & 0.7125 & 0.6418 & 1.110 & 1.146 & -3.11 \\
\hline & 0.31 & 0.7678 & 0.6871 & 1.117 & 1.153 & -3.09 \\
\hline \multirow{3}{*}{45} & 0.23 & 0.6792 & 0.5853 & 1.160 & 1.183 & -1.90 \\
\hline & 0.28 & 0.7233 & 0.6149 & 1.176 & 1.190 & -1.15 \\
\hline & 0.31 & 0.7483 & 0.6306 & 1.187 & 1.202 & -1.25 \\
\hline \multirow{3}{*}{60} & 0.23 & 0.6982 & 0.5705 & 1.224 & 1.233 & -0.70 \\
\hline & 0.28 & 0.7518 & 0.6027 & 1.247 & 1.290 & -3.30 \\
\hline & 0.31 & 0.7956 & 0.6286 & 1.266 & 1.280 & -1.11 \\
\hline \multirow{3}{*}{90} & 0.23 & 0.7191 & 0.5483 & 1.311 & 1.314 & -0.18 \\
\hline & 0.28 & 0.7558 & 0.5711 & 1.323 & 1.359 & -2.62 \\
\hline & 0.31 & 0.7980 & 0.5971 & 1.336 & 1.389 & -3.80 \\
\hline \multirow{3}{*}{120} & 0.23 & 0.6243 & 0.3958 & 1.577 & 1.531 & 3.02 \\
\hline & 0.28 & 0.6748 & 0.4228 & 1.596 & 1.588 & 0.54 \\
\hline & 0.31 & 0.7128 & 0.4438 & 1.606 & 1.625 & -1.15 \\
\hline \multirow{3}{*}{135} & 0.23 & 0.5737 & 0.3459 & 1.659 & 1.786 & -7.13 \\
\hline & 0.28 & 0.6478 & 0.3728 & 1.738 & 1.834 & -5.25 \\
\hline & 0.31 & 0.6976 & 0.3980 & 1.753 & 1.856 & -5.57 \\
\hline \multirow{3}{*}{150} & 0.23 & 0.6217 & 0.3193 & 1.947 & 2.015 & -3.35 \\
\hline & 0.28 & 0.6873 & 0.3508 & 1.959 & 2.053 & -4.55 \\
\hline & 0.31 & 0.7237 & 0.3677 & 1.968 & 2.070 & -4.90 \\
\hline
\end{tabular}

Two monitoring sections are set up at monitoring point $\mathrm{A}$ before bending and monitoring point $\mathrm{B}$ after bending to monitor the overpressure variation law of explosion shock wave and airflow velocity with time, to analyze the attenuation degree of peak overpressure of shock wave at different angles, and to verify the attenuation formula obtained in Section 2.3 experiment. Both monitoring points $\mathrm{A}$ and $\mathrm{B}$ are $1 \mathrm{~m}$ away from the bend.

Figure 8 is the simulation diagram of explosion pressure and airflow velocity propagation at $t=0.8 \mathrm{~ms}, 2.0 \mathrm{~ms}$, $5.4 \mathrm{~ms}, 9.8 \mathrm{~ms}, 12 \mathrm{~ms}$, and $15.1 \mathrm{~ms}$ under the $90^{\circ}$ bend angle and $0.23 \mathrm{~m}^{3}$ gas volume. At the monitoring point $\mathrm{A}$, peak overpressure is $0.613 \mathrm{MPa}$, and peak airflow velocity is $605.43 \mathrm{~m} / \mathrm{s}$. The explosion shock wave and impact airflow propagate along the straight pipe before bending, and the explosion shock wave is the positive shock wave. When $t=$ $10.5 \mathrm{~ms}$, the explosion shock wave goes through a $90^{\circ}$ right bend angle. Under the influence of the bend, the overpressure of shock wave is reflected and refracted to different degrees, forming oblique shock wave. At the bend, the overpressure of shock wave rises sharply, reaching a peak of $1.31 \mathrm{MPa}$, then reflection occurs, and the overpressure is superimposed. Part of the shock wave enters the pipe after bending and attenuates. The impact airflow collides with the wall surfaces, the airflow velocity changes, eddy currents appear, and the kinetic energy decreases. As the explosive airflow constantly rushes into the pipe after bending, the airflow velocity constantly changes, and a local eddy zone is formed at the bend.
As shown in Figures 8(e) and 8(f), with the continuous forward propagation of explosion shock wave, the front shock wave, and explosion airflow resume parallel motion, explosion shock wave changes from oblique shock wave to positive shock wave. At the monitoring point $\mathrm{B}$, peak overpressure at the wave front is $0.553 \mathrm{MPa}$, and peak airflow velocity is $545.84 \mathrm{~m} / \mathrm{s}$.

Figure 9 shows the relationships between explosion overpressure and airflow velocity at different moments at the monitoring points $\mathrm{A}$ and $\mathrm{B}$ before and after the bend. There are two peak overpressures at the monitoring point $\mathrm{A}$, the first peak overpressure is $0.613 \mathrm{MPa}$, and the second peak is $0.578 \mathrm{MPa}$, and it is clear that the second peak is due to the reflection of overpressure at the bend. The impact airflow velocity generated by the explosion creates the local eddy zone at the bend, which consumes a large amount of kinetic energy, and the airflow velocity decreases sharply. The airflow velocity increases slightly after reflecting back from the wall.

3.2.1. Comparison of Numerical Simulation and Experimental Results. Peak overpressure and attenuation coefficient of explosion shock wave with different gas volumes are obtained by simulating seven bend pipes with different angles of $30^{\circ}$, $45^{\circ}, 60^{\circ}, 90^{\circ}, 120^{\circ}, 135^{\circ}$, and $150^{\circ}$. Figure 10 shows the comparison of numerical simulation, experimental results, and model fitting values (calculated with equation (5)). It can be seen that the three results are in good agreement. Some 
scholars have concluded that as long as the relative error between simulation and experimental results is between $-47 \%$ and $+47 \%$, the results obtained by numerical simulation can be applied in the engineering field [35]. Table 4 shows the relative error between the two. It can be seen that the maximum relative error is $7.13 \%$, within $\pm 47 \%$, which indicates that the numerical model and mesh generation are reasonable. This further verifies the correctness of the attenuation coefficient formula obtained in the Section 2.3.

\section{Conclusions}

(1) The explosion shock wave not only reflects but also refracts at the bend. The local resistance produced by the bend has a certain impact on the total energy reduction of gas explosion, and the change of the pipe direction accelerates the attenuation of shock wave

(2) Propagation attenuation of gas explosion in the bend pipe is mainly affected by the bend angle and initial peak overpressure before bending. Peak overpressure of gas explosion in the pipe has an obvious downward trend, and the downward trend increases with the increase of angle. Initial peak overpressure also has a certain influence on the attenuation coefficient of gas explosion; that is, the larger the initial peak overpressure is, the more obvious the attenuation coefficient of gas explosion is

(3) The attenuation degree of explosion shock wave can be characterized by the attenuation coefficient in different bend pipes. With the increase of the bend angle, the attenuation coefficient of explosion shock wave gradually increases. For the same bend angle, the attenuation coefficient increases with the increase of gas volume. The coupling relationships between the attenuation coefficient of peak overpressure, bending angle, and initial peak overpressure at the bend are obtained. This allows the peak overpressure value after a bend to be estimated, which is useful for determining the source location and strength of an explosion in practical applications

(4) The propagation and attenuation law of explosion shock wave are affected by the bent structure of the pipe, which presents certain complexity in the developing process. It is of great significance to find the law of gas explosion shock wave in the pipe for determining the influence scope of gas explosion disaster and disaster prevention and mitigation in coal mines

\section{Data Availability}

The data used to support the findings of the study are included in the article.

\section{Conflicts of Interest}

The authors declare no conflicts of interest.

\section{Acknowledgments}

This research was supported by the National Natural Science Foundation of China (Nos. 51874009, 52074012, 51774014, 51874007, and 51704012), the Opening Project of State Key Laboratory of Explosion Science and Technology (Beijing Institute of Technology) (No.KFJJ20-11M), the Young Elite Scientists Sponsorship Program by China Association for Science and Technology (No.2018QNRC001), the Postdoctoral Fund of Anhui Province (No. 2017B212), and the Natural Science Foundation of the Anhui Higher Education Institutions of China (Nos. KJ2019A0133 and KJ2018A0099).

\section{References}

[1] S. A. Lolon, J. F. Brune, G. E. Bogin Jr., J. W. Grubb, S. A. Saki, and A. Juganda, "Computational fluid dynamics simulation on the longwall gob breathing," International Journal of Mining Science and Technology, vol. 27, no. 2, pp. 185-189, 2017.

[2] Y. Lu, S. Akhtar, A. P. Sasmito, and J. C. Kurnia, "Prediction of air flow, methane, and coal dust dispersion in a room and pillar mining face," International Journal of Mining Science and Technology, vol. 27, pp. 657-662, 2017.

[3] J. L. Kohler, "Looking ahead to significant improvements in mining safety and health through innovative research and effective diffusion into the industry," International Journal of Mining Science and Technology, vol. 25, pp. 325-332, 2015.

[4] S. Z. Yang, G. X. Jing, and Z. W. Jia, "Injury study on impact current of gas explosion in coal mine," Journal of China Coal Society, vol. 34, no. 10, pp. 1354-1358, 2009.

[5] Z. Li, H. Liu, Z. Dun, L. Ren, and J. Fang, "Grouting effect on rock fracture using shear and seepage assessment," Construction and Building Materials, vol. 242, article 118131, 2020.

[6] A. T. Zhou, "Research on propagation characteristics of shock wave and gas flow from gas outburst and induced catastrophic law of mine airflow," China University of Mining and Technology, 2012.

[7] K. Gao, Z. Qi, J. Jia, S. Li, Z. Liu, and Z. Liu, "Investigation of coupled control of gas accumulation and spontaneous combustion in the goaf of coal mine," AIP Advances, vol. 10, no. 4, article 045314, 2020.

[8] M. J. Ajrash, J. Zanganeh, and B. Moghtaderi, "Methane-coal dust hybrid fuel explosion properties in a large scale cylindrical explosion chamber," Journal of Loss Prevention in the Process Industries, vol. 40, pp. 317-328, 2016.

[9] Z. Li, S. Liu, W. Ren, J. Fang, Q. Zhu, and Z. Dun, "Multiscale laboratory study and numerical analysis of water-weakening effect on shale," Advances in Materials Science and Engineering, vol. 2020, Article ID 5263431, 14 pages, 2020.

[10] Q. Meng, H. Wang, M. Cai, W. Xu, X. Zhuang, and T. Rabczuk, "Three-dimensional mesoscale computational modeling of soil-rock mixtures with concave particles," Engineering Geology, vol. 277, article 105802, 2020.

[11] L. Yan, Q. Meng, W. Xu et al., "A numerical method for analyzing the permeability of heterogeneous geomaterials based on digital image processing," Journal of Zhejiang UniversityScience A, vol. 18, no. 2, pp. 124-137, 2017.

[12] B. Q. Lin, C. Guo, Y. M. Sun, C. J. Zhu, Y. D. Hong, and H. Yao, "Effect of bifurcation on premixed methane-air 
explosion overpressure in pipes," Journal of Loss Prevention in the Process Industries, vol. 43, no. 1, pp. 464-470, 2019.

[13] C. Zhu, M. C. He, M. Karakus, X. B. Cui, and Z. G. Tao, "Investigating toppling failure mechanism of anti-dip layered slope due to excavation by physical modelling," Rock Mechanics and Rock Engineering, vol. 53, no. 11, pp. 5029-5050, 2020.

[14] X. Yuan, J. Zhou, Z. Lin, and X. Cai, "Numerical study of detonation diffraction through 90-degree curved channels to expansion area," International Journal of Hydrogen Energy, vol. 42, no. 10, pp. 7045-7059, 2017.

[15] Y. Wang, B. Zhang, S. H. Gao, and C. H. Li, "Investigation on the effect of freeze-thaw on fracture mode classification in marble subjected to multi-level cyclic loads," Theoretical and Applied Fracture Mechanics, vol. 111, article 102847, 2021.

[16] M. G. Yu, W. T. Ji, X. P. Wen, and G. Li, "Experimental study on the effect of staggered obstacles on gas explosion," Journal of China University of Mining and Technology, vol. 42, no. 3, pp. 349-354, 2013.

[17] K. Gao, J. Z. Jia, and Y. H. Liu, "Study on the characteristics of gas secondary explosion caused by explosion shock wave and high temperature coupling," Journal of Safety Science and Technology, vol. 12, no. 4, pp. 35-38, 2016.

[18] Z. D. Lin, R. J. Li, E. L. Liu et al., "Impact of obstacles on shock wave of gas explosion," Journal of Safety Science and Technology, vol. 10, no. 2, pp. 28-32, 2014.

[19] C. Zhu, X. Xu, W. Liu et al., "Softening damage analysis of gypsum rock with water immersion time based on laboratory experiment," IEEE Access, vol. 7, pp. 125575-125585, 2019.

[20] L. Sun, B. Jiang, and F. Gu, "Effects of changes in pipe crosssection on the explosion-proof distance and the propagation characteristics of gas explosions," Journal of Natural Gas Science and Engineering, vol. 25, pp. 236-241, 2015.

[21] Y. S. Zheng and C. Wang, "Numerical simulation for the influence of variable cross-section tube on explosion characteristics of methane," Transactions of Beijing Institute of Technology, vol. 29, no. 11, pp. 947-949, 2009.

[22] H. R. Yin and C. S. Weng, "Propagation characteristic of detonation wave in variable cross-section sudden expansion pipe," Aero Weaponry, vol. 6, pp. 66-72, 2016.

[23] Z. Jia, B. Li, and S. Xu, "Research on gas exploration shock wave spread law via one-way bifurcation pipeline," Advances in Civil Engineering, vol. 2018, Article ID 5012393, 8 pages, 2018.

[24] C. Shi, S. N. Wang, L. Liu, Q. X. Meng, and Q. Zhang, "Mesomechanical simulation of direct shear test on outwash deposits with granular discrete element method," Journal of Central South University, vol. 20, no. 4, pp. 1094-1102, 2013.

[25] S. M. Frolov, V. S. Aksenov, and I. O. Shamshin, "Reactive shock and detonation propagation in U-bend tubes," Journal of Loss Prevention in the Process Industries, vol. 20, no. 4-6, pp. 501-508, 2007.

[26] S. M. Frolov, V. S. Aksenov, and I. O. Shamshin, "Shock wave and detonation propagation through U-bend tubes," Proceedings of the Combustion Institute, vol. 31, no. 2, pp. 2421-2428, 2007.

[27] C. Zhu, Z. Cao, X. Lu, B. Lin, C. Guo, and Y. Sun, "Experimental study on the effect of bifurcations on the flame speed of premixed methane/air explosions in ducts," Journal of Loss Prevention in the Process Industries, vol. 49, pp. 545-550, 2017.

[28] Z. Tao, C. Zhu, M. He, and M. Karakus, "A physical modelingbased study on the control mechanisms of negative Poisson's ratio anchor cable on the stratified toppling deformation of anti- inclined slopes," International Journal of Rock Mechanics and Mining Sciences, vol. 138, article 104632, 2021.

[29] A. Zhou, K. Wang, L. Wang, F. Du, and Z. Li, "Numerical simulation for propagation characteristics of shock wave and gas flow induced by outburst intensity," International Journal of Mining Science and Technology, vol. 25, no. 1, pp. 107-112, 2015.

[30] G. Nicholas and Z. Nicholas, "Quantifying model form uncertainty in Reynolds-averaged turbulence models with Bayesian deep neural networks," Journal of Computational Physics, vol. 383, pp. 125-147, 2019.

[31] A. H. Dastbelaraki, M. Yaghoubi, M. M. Tavakol, and A. Rahmatmand, "Numerical analysis of convection heat transfer from an array of perforated fins using the Reynolds averaged Navier-Stokes equations and large-eddy simulation method," Applied Mathematical Modelling, vol. 63, pp. 660687, 2018.

[32] G. Ciccarelli and S. Dorofeev, "Flame acceleration and transition to detonation in ducts," Progress in Energy and Combustion Science, vol. 34, no. 4, pp. 499-550, 2008.

[33] L. S. Jiang, H. S. Liu, S. Y. Suo, M. Z. Xie, and M. L. Bai, “Simulation of propane-air premixed combustion process in randomly packed beds," Applied Thermal Engineering, vol. 141, pp. 153-163, 2008.

[34] H. Xiao, J. Wang, Z. Liuz, and W. Liu, "A consistent simple algorithm with extra explicit prediction - SIMPLEPC," International Journal of Heat and Mass Transfer, vol. 120, pp. 1255-1265, 2018.

[35] R. KZipf, M. J. Sapko, and J. F. Brune, Explosion pressure design criteria for new seals in US coal mines, National Institute for Occupational Safety and Health, Pittsburgh Research Laboratory, Pittsburgh, PA, U.S., 2007. 